\title{
Psychological Pollution Level Among Sample of Irbid University College Students, in Light of Some Variables
}

\author{
Dr. Abed Al-Nasser Ahmad Al-Azzam \\ Assistant Professor- Al-Balqa' Applied University \\ Abdullah Abdel-Karim Khamis Al-Shoqran \\ Assistant Prof. \\ Al-Balqa Applied University \\ Neda Haza N Al Shammari \\ Ministry of Education-Sudia Arabia
}

\begin{abstract}
This study aimed to discover the level of psychological pollution among Irbid university college female student in light of some variables, the sample of the study consisted of (146) female students from Irbid university college. The researchers used the psychological pollution scale that was developed by them and consisted of (40) items. The results of the study revealed that the level of psychological pollution among Irbid university college female student was intermediate with an average (2.51). also, the results revealed that there were statically significant differences related to the psychological pollution due to major variable and in favour of English students. and the results revealed that there were statically significant differences related to the psychological pollution due to level of study and in favour of fourth year students. The study didn't reveal differences in the level of psychological pollution due to the variable of parents education
\end{abstract}

Keywords: psychological pollution, Irbid University College.

DOI: $10.7176 / \mathrm{JEP} / 10-20-09$

Publication date:July $31^{\text {st }} 2019$

\section{Introduction}

Psychological pollution phenomenon considers one of the important and serious educational phenomena that must be studied and addressed, where it emerged after unusual series of political, social, and cultural circumstances that our societies were affected by, which contributed to the formation of adolescences' behaviors and their psychological structures, through their interaction with it. This led to destabilize the humanity, moral, and religious values system and the emergence of behavioral patterns that weren't familiar in the Jordanian society, which known for maintaining its traditions, customs, and high cultural and human values. Despite that social transformation consider inevitable and natural requirement within the societies, as long as these societies exist but this transition isn't always positive and healthy that goes according to the previously planned frameworks, which reflect development, advancement, and wealth on the society, and isn't a respectful or civilized transformation of social customs and traditions and cultural values, or a transformation that preserves the cultural and social identity, and keep up with the contemporary global changes within awareness and openness (Elwan, 2015), but a negative transformation may comes and get the society involve in a case of imitation without innovation and creativity, which increase the dependency of society on the external world and pollute its principles and values (Sharabi, 1999), and pave the way for a variety of multi social and cultural breakthroughs that happen and threaten the cultural society structure and work to standardize the people's opinion in accordance with foreigner's culture (Al-Shamsi \& Mubarak, 2010). Holding on to the foreign formality manifestations is the biggest gate for anticipating the psychological pollution disease, when we look to the foreigners with formality demonstration as a model to care for and imitate their behaviors, feelings, and their way of thinking, and turn into mere imitators in our societies without the slightest thought (Mohamed, 2004). Psychological pollution may be confused with another concept, which is the mental or intellectual pollution as (Cetin, 2012) referred to and represented by the human exposure to the different visual effects caused by all the existing ways around human, such as common spreading commercials ads and wide influence digital world through its visual and audio contents, which all lead to the mental pollution that affect the human life and thinking. This intellectual pollution may increase in people's daily life at the largest industrialized societies, due to the existing visual incentives and disorder in their environment, and may be associated in one way or another with the psychological pollution concept. Psychological pollution is a concept that simulates the environmental pollution concept, where the nature elements, such as water, air, and soil get contaminated by extraneous elements and spoil its color, taste, or smell, the psychological pollution affect humans as well and defuse them from their pure and clear nature. The human influence by cultural, social, political, and informal environment that surround them and sometimes create a combination of negative behaviors (Mohamed, 2004). Psychological 
pollution is more dangerous than the environmental pollution, it take the soul or self form its roots and origins and progress slowly to turn into a heavy reality that is hard to get rid of. The contamination or pollution of human self means its decomposition and impartiality from the inherent values and replace it with fake, foreign, and corrupt values that pollute the individuals and its implications and effects outrun to infect the society. In this context, the global pollution sources have sought to promote behaviors, agendas, and ideologies and bestow upon it the modernity and contemporary features to draw the desire of societies to it, with the help of some individuals from our society like disloyal, foolish, harassed people who fell for the fake foreign claims and allegation, and this was supported by Arnold Toynbee by displaying the causes of civilization's collapse or incoherence, which attributed according to him to a suicide action of the civilization itself (Zreik, 1980). This where psychological pollution risk or danger reside to convert the people in the society into tools to destroy and sabotage their own society, which is result of their blind imitation of the foreign model.

In view of the fact that individuals consider the basic element of society structure that they live in, the social and cultural transformations affect them and have a crucial role, as it become constructive psychological element whether consciously or not, and from here the fundamental issue arose that related to the construction of personality inner essence (Steinberg, 2005). In this context, Vygotesky mentioned that culture is the critical determinant of individual growth, where culture provide the individuals with the psychological tools of adaptation (Al-Dawahidi, 2005), and Vygotesky also emphasize that social context affects the cognitive development of individuals, and provide them with the thinking methods and mental adaptation tools (psychological tools), which means that culture teach individuals about how then think and what they think (Doolittle, 1997).

Psychological pollution aspects: psychological pollution appears in multiple forms, such as:

- Denial and mistreatment of cultural identity: it show in individuals' refusal of cultural reality and the complaints about social cultures and traditions, and therefore you will see them mistreat themselves permanently, and ashamed of their Arabism, culture, or society (Elwan, 2015 \& Ibrahim, 2016).

- Dangling with western ritual aspects: it shows in individuals' admiration of foreign ritual aspects, borrowing it, and accepting it regardless of its content or its appropriateness to the values and traditions of our societies. It also shows in youth imitation of behavior's styles, haircuts, dresses, and speaking method (Al-Shamsi \& Mubarak, 2010; Mohamed, 2004).

- Faulty sexual stereotypes (virilism): it's individuals' sexual behaviors opposite to the society's expectations, in regard to sex type, or the specific role set in advance for them from the society, like when women lose her femininity (Elwan, 2015).

- Anarchism: it's the behavior that in disagreement with the society's values, roots, and irresponsible behavior (Mohamed, 2004), and its a phenomenon that spread between the youth who suffer from deprivation and stress, where they select this behavior to express themselves, and appear in the societies as a result of the rapid social and cultural changes (Al-Sheiki, 2003; Al-Nawajha, 2017; Schiffer \& Mleeman, 1996).

Psychological Pollution Causes: researchers addressed several reasons that can lead to the psychological pollution, and can be summarized in the following points:

- Unemployment: the growing numbers of unemployed youth and the accumulation of those numbers year after year create a state of anxiety on their future and low self-esteem as a result of their inability to secure the jobs that are appropriate for them and ensure the gracious life for them, which may lead them to escape from the pressures to the alcohol, drugs, or medicines, or engage in marginal jobs in hope to achieve some financial returns, and their unemployment may lead them to withdraw from the society, circumventing the law, fraud, and deceit. Those adolescents can't resist the temptations that offered by the bandits, thieves, or outlaws, in order to encourage them to earn money despite the method they will be using (Shamal, 1999). This was confirmed by each of (Waters \& Moor, 2001) in the strong impact of unemployment on the mental health illness of unemployed individuals.

- Social layers disorder: leads to a breakdown or collapse of social systems and laws, as well as threaten the structure of society and the social cohesiveness, where the individual's social status will be recognized according to the economical resource standard regardless of its source, such as theft, fraud, or corruption. Individual's social status also may be recognized due to their closeness to a senior official in the state, without looking to the individual efficiency or scientific achievement, where singer or dancer could rank at a social status higher than the teacher, or a model may get higher rank than a university professor, therefore youth don't hesitate to engage in unpleasant or shunned acts to earn money and avoid the unemployment (Shamal, 2000).

- Societal crises: lead to increase the chances of psychological pollution due to the crises that occur and raise the life pressures of individuals, which affect their plans and objectives, make it difficult to achieve, and exposes them to frustration and dissatisfaction with their life, and make them lose the meaning of life (Shamal, 2008).

- Poor social integration: the acquisition of a certain class on the privileges and rights of other classes will stir up discontent and anger of disadvantaged groups, in the event of continuing the exploitation of these classes and 
steal their rights and privileges, their feelings of aggression and isolation from society will increase dramatically, and here reside the problem where these marginalized groups will take advantage of every opportunity to jump on the society and rebel on it, and spread a state of disorder and sabotage (Saba, 1999).

\section{Study Problem}

Psychological pollution phenomenon is seen as a psychological and educational phenomenon that need attention due to its significant impact on the behavior of individuals, especially youth, where the negative effects of cultural advancement and the multiple factors that showed through it in the form of racism and modernity played a role in separating youth from their societies and values, misrepresent their identities, and polluted it, as the behavior of young people consider a response to the events that spread through their societies. Researchers noticed that irresponsible openness to the television space with the episodes, movies, and programs that it contain, such as American, Mexican, Turkish, and Japanese within the strange, forbidden, violent, sexual, or superficial contents contribute to the destruction of human, ethical, and religious values, and clearly show in the strange behavior patterns that we see in the Jordanian society. Also the political events in Arabic countries and the conflicts that result from it contributed to force millions of people to migrate to Jordan, and make some transformations on the culture of society, which left negative effects on the behavior of individuals in addition to the crises that Jordan suffer from due to this displacement and migration, such as economical problem, the challenge of terrorism, and the pressure on service sectors, like health, education, water, and roads. All of that and more led to the appearance of strange and unusual behaviors, and in contrary to their values and culture. Instability deepen in the hearts and souls of young people conflicting psychological feelings toward the society and the mutual relationships in it, where the crises and pressure liberate the behavior from values, norms, and standards that govern it, and threaten the society of negative behaviors which result from the psychological pollution that infected the young people or youth.

\section{Study Questions}

This study has the following two questions:

$1^{\text {st }}$ question: What is the psychological pollution level among a sample of BAU students?

$2^{\text {nd }}$ question: Is the psychological pollution level varying according to the difference in study major, school year, or education level of parents?

\section{Study Importance \\ 4.1 Theoretical Importance:}

The importance of this study stems from being the first study in Jordan, according to the researcher knowledge that dealt with the psychological pollution topic, and one of the few studies in the Arab world, where the psychology literatures are short of this topic. The concept of psychological pollution is one of the modern educational concepts and the non-popular. This study important comes from addressing an important sample of university students (youth), who are nation's pillar, hopes built on them, they are tools for building homelands, and a way to raise the countries, which is a great responsibility that lays on them toward their countries, and it's not permitted to ignore this important segment to avoid turning young people into tools to demolish and destroy their countries. This study also provides the theoretical literature of modern topic that benefits the educators and graduate students. In addition, the results of this study provide data that benefit state officials and society leaders to deal with youth.

\subsection{Practical Importance:}

This study will contribute by helping the educational professionals and experts to identify the aspects of psychological pollution among college students. It also help decision makers in the universities to take a group of procedures related to the curricula and activities that promote the noble psychological structure and safeguard the youth from the psychological pollution phenomenon.

\section{Theoretical Framework \\ 5.1 Procedural Definitions:}

Psychological pollution: it's a group of negative input adopted by individuals, such as behavior and mindset to influence the cultural identity foundation of those individuals, as a reflection of social structure across the country (Mohamed, 2004, 27-28). (Ibrahim, 2016) identify it as a faulty situation that happen on the psychological environment structure, due to irrelevant external factors that lead to the disorder and the negative impact in its adaptation and balance with the reality, where the disorder happen as an occasional or incidental result of interference between the appearance and content of thought and behavior, while researchers define the psychological pollution as a disorder in the psychological environment, due to the interference of external cultural, social, economical, and intellectual factors that cause disorder and adaptation disturbance, and result in 
denial and abuse of cultural identity, and hang on to the foreign formality aspects, and procedurally it defines as the degree which study sample members respond to on the psychological pollution scale developed by the researchers.

\subsection{Study limitations:}

The current study limitations represented in the following:

- Human boundaries: BAU students/Irbid University College represented in the Arabic and English language majors of study.

- Spatial boundaries: the Hashemite Kingdom of Jordan/Irbid governorate.

- Temporal boundaries: the academic year 2018.

\subsection{Study determinants:}

The dissemination of results is determined by depending on the characteristics of the study sample and its degree of representation of the study population, in addition to the study tools and its psychometric characteristics.

\section{Previous Studies}

Psychological pollution consider a very important concept, but the interest in it may hasn't arrive to the required status despite its importance and its impact on the societies and generations, and after the intensive research from researchers it show a lack of adequate studies on this topic, where most studies were found in the Iraq areas and few of it elsewhere, and the following is a presentation of those studies:

Al-Taraia (2001) conducted a study that entitled "Modern trends among University of Mosul students and its relationship with some variables", where the study sought to differentiate the direction of modernity from the traditional and transitional trends, by implementing the modernity trend measurement prepared by Smith (1976, which consist of (24) areas on a sample of (477) male and female students from the Mosul University. Study results showed the existance of relationships between the (24) measurement areas, and the modernity ratio for each of the following concepts (consumption trend, dignity, citizenship, women's rights, opinion growth, planning) were $(73 \%, 56 \%, 55 \%, 54 \%, 47.5 \%, 30 \%)$ respectively.

Mohamed (2004) conducted a study that aimed to build a psychological pollution scale, on a sample of (1546) University of Mosul male and female students. The psychological pollution scale that was prepared by the researcher and consisted of (118) items was used, and the study results showed that psychological pollution level among Mosul University students reached (54.25\%),and at medium degree. Results also showed differences in the psychological pollution, due to the sex variable, and in favor of male with an average of $(68.32 \%)$ versus $(45.16 \%)$ for females, where the psychological pollution attributed in the study for students in the scientific majors, and in favor of fourth year students who are Mosul city residents.

Al-Shamsi \& Mubarak (2010) did a study that entitled "psychological pollution among Baghdad University students" to identify the psychological pollution level among the university students, and the study sample consisted of (411) male and female students where the psychological pollution scale was applied on them. Study results didn't show that sample members are characterized with the psychological pollution. Results also showed no differences in the psychological pollution between males and females, while there were differences in psychological pollution level in favor of humanity majors.

Mubarak (2010) conducted a study that entitled "psychological pollution and its relationship with the parental treatment patterns among the University of Baghdad students" to detect the psychological pollution level and the parental treatment patterns among the university students, where the study sample consisted of (70) male and female students, and Mohamed (2004) psychological pollution scale was used. Study results showed a low level of psychological pollution among University of Baghdad students, and showed no differences in the psychological pollution, due to the sex and educational level variables, while the results showed a statistically significant difference due to the humanity major variable.

Shehab \& Al-Obeidi (2011) study also aimed to measure the level of psychological pollution and its relationship with the emotional maturity among the teacher training institute and the fine arts institute students at Nineveh governorate. The study sample consisted of (480) male and female students, and the psychological pollution scale which contain (100) items and developed by the researchers was implemented on them, and also used the emotional maturity scale, which was developed by the researchers. Study results showed that level of psychological pollution among students of teacher training institutes and the institute of fine arts was high, and it showed differences in the psychological pollution level attributed to sex variable, and in favor of males, and also differences due to the education level variable, and in favor of the second and third levels.

Alwan (2015) also conducted a study that entitled "Histrionic or Borderlines Personality and its relationship with the psychological pollution among low and high self concept university students", where the research sample consisted of (500) male and female students who were selected by the random stratified method from 
Baghdad University students, and the researcher used each of the histrionic personality, psychological pollution, and self concept scales. Study results showed statistically significant differences between the low and high self concepts of the psychological pollution, and in favor of low self concept. It also showed statistically significant differences between the histrionic personality and psychological pollution, and it showed a correlation between the histrionic personality and psychological pollution at low and high self concepts.

Ibrahim (2016) conducted a study that aim to measure the psychological pollution among kindergarten department students, where the study sample consisted of (678) female students from the basic education college at the Mustansiriyah University, and college of education for girls at the University of Baghdad, and the psychological pollution scale prepared by Mohamed (2004) was implemented on them. The study results showed absence of statistical significance in the psychological pollution level of variables, while the results showed that $(40 \%)$ of the respondents have psychological pollution.

The study of Al-Nawajha (2017) aimed to identify the level of psychological pollution among the unemployed university graduates at Rafah governorate, and find the differences in the psychological pollution according to the sex, marital status, qualifications, and years of unemployment variables. Study implemented on a random sample of unemployed (300) male and female university graduates, and used the psychological pollution scale, which was prepared by the researcher in the study. The study results indicated a high level of psychological pollution at the two aspects of "denial of identity \& sticking to the formal foreign aspects", and also showed differences in pollution, in favor of both males and singles.

It show from reviewing the previous studies that the majority of it aimed to measure the psychological pollution level and its relationship with other variables, and most of the studies related to the psychological pollution concept are centered in Iraq, with no studies that were conducted in Jordan, and only one study was conducted outside of Iraq, which is Al-Nawajha (2017) study that was conducted in Palestine. The majority of studies have shown differences in its results, where the results of some studies have showed that males have psychological pollution but females didn't have pollution, some studies showed a level of psychological pollution among fourth year students greater than the previous years' students, and some studies also showed no psychological pollution among its sample. The current study differ from other studies that it's the only one that examine the psychological pollution among two samples of Arabic and English language students, through the descriptive survey study, and it's the first study, according to the researchers knowledge that has been conducted in Jordan.

\section{Study Methodology}

The study methodology include a description of the study population and the study sample, it include a description of the study tools, procedures, and variables, and also the statistical methods that will be used to analyze the study results. The descriptive survey method was used by relying on the survey studies due to its alignment with the study objectives and questions.

\subsection{Study Population \& Sample:}

The study population consisted of all (659) Arabic and English language female students at Irbid University College, with (303) Arabic language students and (356) English student.

But the study sample was selected with the simple random method from the study population, and consisted of (146) female students, and the following table illustrates the sample member's distribution.

Table (1) distribution of study sample members according to the personal variables $(n=146)$

\begin{tabular}{|c|c|c|c|}
\hline Variable & Level & Frequency & Percentage \\
\hline \multirow{3}{*}{ Major of Study } & Arabic Language & 70 & 47.9 \\
\hline & English Language & 76 & 52.1 \\
\hline & Total & 146 & 100 \\
\hline \multirow{5}{*}{ Year of Study } & First & 2 & 1.4 \\
\hline & Second & 48 & 32.9 \\
\hline & Third & 59 & 40.4 \\
\hline & Fourth & 37 & 25.3 \\
\hline & Total & 146 & 100 \\
\hline \multirow{3}{*}{$\begin{array}{l}\text { Father } \\
\text { Level }\end{array}$} & High School Diploma \& less & 60 & 41.1 \\
\hline & University Education & 86 & 58.9 \\
\hline & Total & 146 & 100 \\
\hline \multirow{3}{*}{$\begin{array}{l}\text { Mother } \\
\text { Level }\end{array}$} & High School Diploma \& less & 67 & 45.9 \\
\hline & University Education & 79 & 54.1 \\
\hline & Total & 146 & 100 \\
\hline
\end{tabular}




\subsection{Study Tool:}

Psychological pollution scale:

Psychological pollution scale was developed by returning back to a series of studies that related to the research topic, such as Shehab \& Al-Obeidi (2011), (Al-Shamsi \& Mubarak, 2010), Mohamed (2004), and Elwan (2015) study, where the scale consist of (40) items that were distributed on two dimensions:

First: shock dimension: It represents a case of tension and confusion in dealing with the reality that individual's experience, which affect their performances with the declaration of rejection vocally.

Second: shock effects dimension: It represent a case of inner discord, asymmetry, and interruption of individual emotion toward the past, present and future, with taking into account that measurement items are appropriate with the contents of psychological pollution concept, which is a type of subjective report that students respond to, in light of the fifth Likert scale: strongly agree (5), agree (4), neutral (3), disagree (2), and strongly disagree (1), knowing that the scale was reversed for the items that carry an opposite meaning, and the following formula was used to extract the range for each one of the three levels:

Length of Period $=($ Alternative maximum limit- alternative minimum limit $) /$ number of required levels Length of Period $=(5-1) / 3=1.33$, therefore the levels will be as follows:

From 1 to less than 2.33 is low level.

From 2.33 - less than 3.66 is medium level.

From 3.66-5 is high level.

\subsection{Tool sincerity:}

\subsubsection{Virtual sincerity:}

Test sincerity (virtual sincerity) was verified by introducing the tool on a group of arbitrators, in the area of education and psychology to take their views and opinions about the suitability of items to the areas that belong to, its language integrity, and make the appropriate changes in term of paraphrasing, deleting, merging, or adding new items, and in term of its representation and appropriateness to the category that study sample belongs to. Based on the reviews and notes of arbitrators, we kept all paragraphs that got $(80 \%)$ agreement or higher with making some language modifications, in certain paragraphs or items such as paragraph (3), which was (when I travel outside of Iraq I try to hide my nationality) and it become after the adjustment (when I travel outside the country I try to hide my nationality), and paragraph (6) which was (My society members are committed to the characteristics of religions) and became after the adjustment (My society members are religious), and paragraph (11) was (Everyone don't invest their money well) and become after the adjustment (no one invest money well).

\section{Structural sincerity:}

After ensuring virtual sincerity of the study tool, it was implemented as a field study on the exploratory sample of (25) female students from outside the study sample to verify the internal consistency sincerity, where the sincerity of the questionnaire statements were measured by the correlation coefficient between the expression level and the overall degree, as shown in table (2):

Table (2) correlation coefficients between the degree of each study tool item within the overall degree of the tool

\begin{tabular}{|c|c|c|c|}
\hline Number & $\begin{array}{c}\text { Correlation Coefficient with the } \\
\text { tool }\end{array}$ & Number & $\begin{array}{c}\text { Correlation Coefficient with the } \\
\text { dimension }\end{array}$ \\
\hline 1 & $* 0.50$ & 23 & $* 0.66$ \\
\hline 2 & $* 0.55$ & 24 & $* 0.80$ \\
\hline 3 & $* 0.56$ & 25 & $* 0.72$ \\
\hline 4 & $* 0.31$ & 26 & $* 0.79$ \\
\hline 5 & $* 0.54$ & 27 & $* 0.78$ \\
\hline 6 & $* 0.57$ & 28 & $* 0.79$ \\
\hline 7 & $* 0.45$ & 29 & $* 0.60$ \\
\hline 8 & $* 0.64$ & 30 & $* 0.63$ \\
\hline 9 & $* 0.63$ & 31 & $* 0.66$ \\
\hline 10 & $* 0.65$ & 32 & $* 0.64$ \\
\hline 11 & $* 0.64$ & 33 & $* 0.71$ \\
\hline 12 & $* 0.47$ & 34 & $* 0.74$ \\
\hline 13 & $* 0.51$ & 35 & $* 0.25$ \\
\hline 14 & $* 0.37$ & 36 & $* 0.76$ \\
\hline 15 & $* 0.45$ & 37 & $* 0.78$ \\
\hline 16 & $* 0.44$ & 38 & $* 0.70$ \\
\hline 17 & $* 0.58$ & 39 & $* 0.77$ \\
\hline 18 & $* 0.48$ & 40 & \\
\hline
\end{tabular}




\begin{tabular}{|c|c|c|c|}
\hline Number & $\begin{array}{c}\text { Correlation Coefficient with the } \\
\text { tool }\end{array}$ & Number & $\begin{array}{c}\text { Correlation Coefficient with the } \\
\text { dimension }\end{array}$ \\
\hline 19 & $* 0.40$ & & \\
\hline 20 & $* 0.45$ & & \\
\hline 21 & $* 0.45$ & & \\
\hline 22 & $* 0.33$ & & \\
\hline
\end{tabular}

* Statistically significant at level $(\alpha \leq 0.05)$

It shows from table (2) that all correlation coefficient between the item degree and the tool as a whole is statistically significance at level $(\alpha \leq 0.05)$, which indicate the internal consistency between the items contain in the questionnaire and its structurally sincere, and consider valid to be implemented on the study members.

Tool Constancy:

Test-Retest method was used to verify the consistency of the scale and its implementation by implementing it twice on an exploratory sample, which consist of (25) female students from outside the study sample within two weeks interval, and the correlation coefficient was retrieved using Pearson Correlation between their estimations at both times on the study tool as a whole, where the correlation coefficient between the two implementations of the tool amounted to $(0.85)$, which is a statistically significance value at level $(\alpha=0.05)$. Cronbach Alpha test was implemented on all items of the study tool, and shows that consistency coefficient of the tool as a whole reached $(0.83)$, which is a high and acceptable value for the implementation purposes.

\section{Study Results and Discussion}

This section include a demonstration of the study results, which aim to identify the psychological pollution among a sample of BAU students, in light of some variables, and the results will be displayed according to the questions that were addressed in the study.

Results of the first question: What is the psychological pollution level among a sample of BAU students? To answer this question, the arithmetic means and standard deviations was extracted for the sample members' responses on the study tool items, and the tool as a whole, which aimed to identify the psychological pollution, as shown in table (3):

Table (3) arithmetic means and standard deviations for the sample members' responses on the study tool items, and the tool as a whole arrange in descending order according to the arithmetic mean $(n=146)$

\begin{tabular}{|c|c|l|c|c|c|}
\hline Rank & Number & \multicolumn{1}{|c|}{ Item } & Mean & STDEV & Level \\
\hline 1 & 7 & People are quoting the reality and they are not creative & 1.02 & 3.54 & Medium \\
\hline 2 & 15 & $\begin{array}{l}\text { Religious places are for tourism and trade more than } \\
\text { worship }\end{array}$ & 1.15 & 3.52 & Medium \\
\hline 3 & 14 & My society members believe in superstition and sorcery & 1.04 & 3.49 & Medium \\
\hline 4 & 28 & Most of our culture are foreign and strange & 1.09 & 3.47 & Medium \\
\hline 5 & 1 & $\begin{array}{l}\text { I feel annoyed for not being able to use sophisticated } \\
\text { equipments }\end{array}$ & 1.26 & 3.44 & Medium \\
\hline 6 & 2 & Holding on to the social customs discomfort me & 1.23 & 3.30 & Medium \\
\hline 7 & 5 & $\begin{array}{l}\text { Harmony and compatibility between my society members } \\
\text { is weak }\end{array}$ & 1.20 & 3.18 & Medium \\
\hline 8 & 16 & Sacrifice for others is not a duty & 1.14 & 3.16 & Medium \\
\hline 9 & 33 & I think that society isn't committed to cultural values & 1.09 & 3.08 & Medium \\
\hline 10 & 6 & My society members are characterized as religious & 0.91 & 3.00 & Medium \\
\hline 11 & 34 & $\begin{array}{l}\text { The country that has no historical places is without } \\
\text { civilization }\end{array}$ & 1.10 & 3.00 & Medium \\
\hline 12 & 4 & I think most of my society youth are corrupt and abusive & 1.10 & 2.99 & Medium \\
\hline 13 & 36 & Foreigners plan better for my future & 1.39 & 2.98 & Medium \\
\hline 14 & 11 & No one invest their money well & 0.96 & 2.97 & Medium \\
\hline 15 & 17 & $\begin{array}{l}\text { I believe in the common saying (Jordanian don't need } \\
\text { chair \& table) }\end{array}$ & 1.31 & 2.95 & Medium \\
\hline 16 & 18 & Everybody don't invest their money well & 0.94 & 2.92 & Medium \\
\hline 17 & 40 & $\begin{array}{l}\text { I find that most of what our history translates to us is } \\
\text { unreal. }\end{array}$ & 1.15 & 2.86 & Medium \\
\hline 18 & 35 & $\begin{array}{l}\text { English language is more important than the Arabic } \\
\text { language }\end{array}$ & 1.35 & 2.71 & Medium \\
\hline 19 & 39 & Foreigner own better mental skills than my countrymen & 1.33 & 2.69 & Medium \\
\hline 20 & 22 & Lying has become necessary to deal with others & 1.26 & 2.64 & Medium \\
\hline
\end{tabular}




\begin{tabular}{|c|c|l|c|c|c|}
\hline Rank & Number & \multicolumn{1}{|c|}{ Item } & Mean & STDEV & Level \\
\hline 21 & 25 & $\begin{array}{l}\text { I care about the quick profit more than the university } \\
\text { degree }\end{array}$ & 1.38 & 2.50 & Medium \\
\hline 22 & 21 & Human that is committed towards others consider fool. & 1.40 & 2.48 & Medium \\
\hline 23 & 38 & $\begin{array}{l}\text { Individuals consider successful whenever they committed } \\
\text { to their culture }\end{array}$ & 1.10 & 2.26 & Low \\
\hline 24 & 30 & The society that doesn't have a civilization is a loser & 1.23 & 2.21 & Low \\
\hline 25 & 10 & My country's enemies aren't necessarily an enemy for me & 1.26 & 2.19 & Low \\
\hline 26 & 19 & I abandon my principles in the difficult circumstances & 1.19 & 2.05 & Low \\
\hline 27 & 13 & Others recognize the concept of culture confusedly & 0.79 & 2.02 & Low \\
\hline 28 & 23 & Deception is important when dealing with others & 1.10 & 2.01 & Low \\
\hline 29 & 8 & I think that the whole world is an enemy of mine & 1.04 & 1.92 & Low \\
\hline 30 & 12 & My society members determine freedom in a wrong way & 0.89 & 1.90 & Low \\
\hline 31 & 32 & The future of nation is an extension of its past and present & 0.89 & 1.79 & Low \\
\hline 32 & 20 & I care about the outside of human more than the inside & 1.01 & 1.76 & Low \\
\hline 33 & 27 & $\begin{array}{l}\text { Commitment of society to history and culture is evidence } \\
\text { of its weakness }\end{array}$ & 0.89 & 1.72 & Low \\
\hline 34 & 31 & The building of nation depends on the past and present & 0.85 & 1.67 & Low \\
\hline 35 & 37 & Historical sites is a need that must be preserved & 0.80 & 1.64 & Low \\
\hline 36 & 26 & My country has a beautiful past & 0.82 & 1.52 & Low \\
\hline 37 & 29 & I am proud of the history and civilization of my country & 0.74 & 1.50 & Low \\
\hline 38 & 3 & $\begin{array}{l}\text { Whenever I travel outside of the country, I try to hide my } \\
\text { nationality }\end{array}$ & 0.83 & 1.47 & Low \\
\hline 39 & 24 & I consider the smoking of children normal & 0.79 & 1.32 & Low \\
\hline 40 & 9 & $\begin{array}{l}\text { It upset me whenever my countrymen achieve a great } \\
\text { accomplishment }\end{array}$ & 0.56 & 1.25 & Low \\
\hline & & & $\mathbf{0 . 3 5}$ & $\mathbf{2 . 5 1}$ & Medium \\
\hline
\end{tabular}

It shows from table (3) that arithmetic means for the sample members' responses on the study tool items, and the tool as a whole range from (1.25-3.54), which aimed to identify the psychological pollution level among sample of BAU students. Item (7) "people are quoting the reality and they are not creative" came in the first place with an arithmetic mean of (3.54) and a medium level, and in second place came item (15) "Religious places are for tourism and trade more than worship", with an arithmetic mean of (3.52) and also medium level, while item (14) "My society members believe in superstition and sorcery" came third with a arithmetic mean of (3.49) and medium level, but item (9) "It upset me whenever my countrymen achieve great accomplishment" came in last place with an arithmetic mean of (1.25) and a low level. Arithmetic mean for the tool as a whole amounted to (2.51) at medium level, which indicate a medium psychological pollution level among the sample of BAU students.

Researchers explain that students got a medium level of psychological pollution by saying that result was logical, due to the pressures that students face, such as television and radio programs, and social network sites, which offer them many of the diverse ideas, and a different and strange culture from their society, and its traditions and customs, which become at the present time a significant factor in the personality formation of youth and their thoughts, and therefore all of these factors contributed to the psychological pollution entrance to the university students. Researchers believe that without the good education which students received in their homes, and without the conservative life that our societies live, which put emphasis on the good customs and traditions, respect of society directions, and the commitment to religion and its teachings, the psychological pollution levels were much higher. In addition, the contribution of university to the awareness, guidance, and direction of students have alleviated the impact level of psychological pollution factors on them.

The non-directed technology and media openness contributed heavily to the attachment of youth to the Western lifestyles and its ideas, where we see them imitate the world stars in their haircuts, dresses, and lifestyles considering them prototypes of urbanization and moderation which must keep pace with and imitate. It also forces them to abandon their parents and grandparents life, and seeing it as an old style that doesn't fit them as a new generation. Its possible that current wars and conflicts of the region, and the resulting low level of education and health services may be the reason for creating a situation of psychological instability among youth, which made them feel uncomfortable and have the desire to travel and live in other countries that have the conditions for more prosperous life. Unemployment may be one of the reason for psychological pollution that had affect on the students, where it's no secret that unemployment rates are increasing every year between educators and graduates with the absence of any government plan to tackle this problem, which made the students who are still studying aware of this fact, and start to feel the worthlessness of their studies, where there will be no jobs after 
all these troubles, and the employment path is close. These results agreed with the results of Mohamed (2004) and Elwan (2015) studies, and disagreed with Al-Shamsi \& Mubarak (2010) study results.

Results of the second question: Are there any statistically significant differences at level $(\alpha \leq 0.05)$ of the psychological pollution level among a sample of BAU students, according to the variables of study major, school year, or education level of parents?

- According to the variable of study major:

To answer this question, Independent Samples T-Test was implemented on the tool as a whole, according to the major of study variable, which shown through table (4) below:

Table (4) Independent Samples T-Test implementation results on the tool as a whole, according to the major of study variable

\begin{tabular}{|l|c|c|c|c|}
\hline Major of study & Mean & STDEV & T & Sig \\
\hline Arabic language & 2.45 & 0.32 & 2.35 & 0.02 \\
\hline English language & 2.58 & 0.36 & & \\
\hline
\end{tabular}

It shows from table (4) statistically significant differences at level $(\alpha \leq 0.05)$ of the psychological pollution level among a sample of BAU students, according to the major of study variable with a $(\mathrm{T})$ value of $(2.35)$, which is statistically significant value, and by reviewing the arithmetic means it show that the differences are in favor of English language major at (2.58), which indicate that the psychological pollution level among a sample of BAU students of the English language major are higher than the students of Arabic language major.

According to the researchers point of view, they explained this result with the fact that English language students are more familiar and enlighten with the Western culture, and more expose and influence to it, due to the nature of their major of study, where for an example they study the English literature and learn about their culture through it, which leave impact and possibly admiration of it. Studying the English language and checking out the foreign films which contain messages that carry the culture of this society may affect students, and increase their connection and attachment with the Western culture, its concepts, and lifestyle. Arabic language students are on the opposite of that, where they study the ancient Arabic texts, alshr-aljahly or old ages poetry, and Arabic literature which contain the scripts and stories that put emphasis on our values, religion, traditions, deep history, and sober-minded culture, which promote the Arabic identity, therefore the level of psychological pollution came less among the students of Arabic language major. We didn't find any study that addresses the psychological pollution level, according to the major of study variable (Arabic/English language).

- According to the year of study variable:

Variance analysis (ANOVA) was implemented on the tool as a whole, according to year of study variable, as shown in the tables (5-6) below:

Table (5) arithmetic means and standard deviations for the study sample members' responses on the tool as a whole, according to the study year variable

\begin{tabular}{|l|c|c|}
\hline Year of study & Mean & STDEV \\
\hline First & 2.38 & 0.46 \\
\hline Second & 2.47 & 0.27 \\
\hline Third & 2.40 & 0.31 \\
\hline Fourth & 2.75 & 0.37 \\
\hline
\end{tabular}

It shows from table (5) the existence of virtual differences between the arithmetic means of psychological pollution level, according to the year of study variable, and to identify the statistical significance of these differences, the one-sided variance analysis (ANOVA) were implemented, as shown in table (6) below:

Table (6) one-sided variance analysis (ANOVA) implementation results on the tool as a whole, according to year of study variable

\begin{tabular}{|c|c|c|c|c|c|}
\hline Source of Variance & Sum of squares & DF & Mean squares & F & Sig \\
\hline Between groups & 3.05 & 3 & 1.02 & 10.07 & 0.00 \\
\hline Inside groups & 14.35 & 142 & 0.10 & & \\
\hline Total & 17.40 & 145 & & & \\
\hline
\end{tabular}

* Statistically significance at level $(\alpha \leq 0.05)$

It show from table (6) statistically significant differences at level $(\alpha \leq 0.05)$ of the psychological pollution level, according to year of study variable, where $(F)$ value amounted to (10.07) and its statistically significant at level $(\alpha \leq 0.05)$, and to identify the sources of difference or variation; the Scheffe method of dimensional comparisons was implemented on the level of psychological pollution, according to the year of study variable, as shown in table (7) below: 
Table (7) results of implementing Scheffe method of dimensional comparisons on the psychological pollution level, according to year of study variable

\begin{tabular}{|l|c|l|c|c|c|}
\hline Year of study & Mean & First year & Second year & Third year & Fourth year \\
\hline First & 2.38 & & -0.09 & -0.02 & $-0.37^{*}$ \\
\hline Second & 2.47 & & & 0.07 & $-0.28^{*}$ \\
\hline Third & 2.40 & & & & $-0.35^{*}$ \\
\hline Fourth & 2.75 & & & & \\
\hline
\end{tabular}

* Statistically significance at level $(\alpha \leq 0.05)$

It show from table (7) that sources of the differences or variations were between the fourth study year, and each of the (first, second, third) study years, and in favor of the fourth study year with an arithmetic mean of (2.75), which indicate that level of psychological pollution among fourth year students was higher than the other years.

Researchers see that fourth year students are better inform about the various aspects of life, due to the longer period that they spent at the university, where fourth year English language students are more in depth, more knowledgeable about the foreign literature and intellectual topics, and more saturated from previous years students. Also, as the students approach the end of study life and join the workforce, they may start to think about the available job opportunities and get surprise that unemployment rates are increasing continuously, which make them feel discontent on their reality, and may hate this reality and blame it on their countries and governments. As mentioned earlier in this search, the unemployment is one of the reasons for psychological pollution, where the inability of students to work and satisfy their selves is an issue that lead to low self esteem of students, especially after they face the question of the society, what university degree have done for you? This question may indicate that society doesn't respect science, education, and educators, where this result agreed with Mohamed (2004) study results.

- According to the education level of parents variable:

To answer this question, Independent Samples T-Test was implemented on the tool as a whole, according to the two variables (education level of father, education level of mother), which shown through table (8) below:

Table (4) Independent Samples T-Test implementation results on the tool as a whole, according to the two variables (education level of father, education level of mother)

\begin{tabular}{|l|l|c|c|c|c|}
\hline Variable & Education level & Mean & STDEV & T & Sig \\
\hline \multirow{2}{*}{$\begin{array}{l}\text { Father } \\
\text { education }\end{array}$} & Tawjihi diploma or less & 2.54 & 0.36 & 0.98 & 0.33 \\
\cline { 2 - 6 } $\begin{array}{l}\text { Mother } \\
\text { education }\end{array}$ & University education & 2.49 & 0.34 & & \\
\cline { 2 - 6 } & Tawjihi diploma or less & 2.55 & 0.36 & 1.47 & 0.14 \\
\hline
\end{tabular}

It shows from table (8) the nonexistence of statistically significant differences at level $(\alpha \leq 0.05)$ of the psychological pollution level among a sample of BAU students, according to the two variables (education level of father, education level of mother) where (T) value wasn't statistically significant.

Researchers believe that parental role in influencing their children move back due to the power of media, progress in the area of communication, and social network sites, and also psychological pollution reasons have an effect on students regardless of their parents' level of education, where students influence by the reasons of psychological pollution, such as unemployment, social stratification disorder, society crises, and poor social integration are all reasons that affect youths, and parents can't persuade their children that these things won't reach or affect them, therefore no differences show in favor of parents education level.

\section{Recommendations}

In light of the study results, researchers recommend the following:

1. Give the topic of psychological pollution greater attention through the awareness about it in society, and its effects on the younger generation.

2. The awareness of psychological pollution methods and its impact on students by providing subjects or courses related to this topic to reduce its negative effects on the students.

3. Examine the concerned parties of technological communication channels and various social media, by setting the determinants and specifications to prevent the spreading of its harmful effects on society.

4. Deepen and strengthen the Arabic Islamic civilization values, which associated with our social reality in the Jordanian environment.

5. The need to conduct similar studies in different societies.

\section{References}

1. Al-Dawahidi, Azmi (2006), "The effectiveness of teaching according Vygotesky theory to gain some environmental concepts among Al-Aqsa University female students of Gaza", unpublished master thesis, 
Islamic University, Gaza, Palestine

2. Al-Nawajha, Zuhair Abdul Hamid (2017), "Psychological pollution among the unemployed university graduates at Rafah governorate", psychological and educational science journal, volume 4, issue, p. 267289

3. Al-Shamsi, Abid Al-Ameer \& Mubarak, Ahmed (2010), "Psychological pollution among the University of Baghdad students ", Faculty of education Journal, University of Baghdad, Iraq

4. Al-Sheiki, Hasan (2003, "The non-standardization (Alanomi), self-concept, and the behavior among delinquents and non-delinquents in Riyadh city", Unpublished master thesis, Naif University for Security Sciences, Saudi Arabia.

5. Al-Taraia, Ahmed (2001), "Modern Trends among Mosul University students and its relationship with some variables", unpublished Master thesis, University of Mosul, Iraq.

6. Elwan, Talal (2015), "The phony Personality and its relationship with the psychological pollution among low and high self concept of among university students", unpublished PhD thesis, Faculty of education, University of Baghdad.

7. Ibrahim, Yasmin Taha (2016), "Measuring psychological pollution among kindergarten department female students", Mustansiriyah literature magazine, Mustansiriyah University, issue 74, p. 1-47

8. Mohamed, Osama Hamed (2004), "Psychological pollution among Mosul University students", unpublished $\mathrm{PhD}$ thesis, Faculty of education, University of Mosul.

9. Mubarak, Ahmed Nasr (2010), "Psychological pollution and its relationship with the parental treatment patterns among the University of Baghdad students", Unpublished master thesis, Faculty of education/Ibn Rushd, Baghdad University.

10. Saba, Elias (1999), "The future of economical situations in Lebanon", Al Mustaqbal Al Arabi journal, Baghdad, issue 143, p.104-105

11. Schaefer, Sharlo \& Mailman, Howard (1996), "Children and adolescents problems and methods to solve it", translated by: Nassima Daoud \& Nazeh, Hamdi, University of Jordan, Jordan

12. Shamal, Mahmoud Hassan (1999), "Future concern among the young graduates from universities", Al Mustaqbal Al Arabi journal, issue (249), p. 70-85

13. Shamal, Mahmoud Hassan (2000), "Youth and the alienation problem at the Arab society", Monthly cultural series issued by the Dar public cultural affairs, cultural encyclopedia

14. Sharabi, Hisham (1999), "Cultural critique of Arab society at the end of twentieth century", Second Edition, Beirut, Arabic Unity Studies Center

15. Shehab, Shahrzad \& Al-Obeidi, Zhour (2011), "Psychological pollution and its relationship with the emotional maturity among the students of teacher training institutes and fine arts institutes at Nineveh governorate center", Educational studies, University of Mosul, issue 14, p. 11-38

16. Zreik, Constantine (1980), "W are the Future", Second Edition, Beirut, Dar Al Malayin 